\title{
Error estimates for approximating best proximity points for cyclic contractive maps
}

\section{BOYAN ZLATANOV}

\begin{abstract}
.
We find a priori and a posteriori error estimates of the best proximity point for the Picard iteration associated to a cyclic contraction map, which is defined on a uniformly convex Banach space with modulus of convexity of power type.
\end{abstract}

Acknowledgements. This research is partially supported by Grant 146/2015 of National Science Fund of Sofia University and by Plovdiv University Paisii Hilendarski NPD Project NI15-FMI-004.

\section{REFERENCES}

[1] Beauzamy, B., Introduction to Banach Spaces and their Geometry, North-Holland Publishing Company, Amsterdam, 1979

[2] Berinde, V., Iterative Approximation of Fixed Points, Springer, Berlin, 2007

[3] Deville, R., Godefroy, G. and Zizler, V., Smothness and renormings in Banach spaces, Pitman Monographs and Surveys in Pure and Applied Mathematics, 1993

[4] Eldred, A. and Veeramani, P., Existence and convergence of best proximity points, J. Math. Anal. Appl., 323 (2006), No. 2, 1001-1006

[5] Fabian, M., Habala, P., Hájek, P., Montesinos, V., Pelant, J. and Zizler, V., Functional Analysis and InfiniteDimensional Geometry, Springer-Verlag, New York, 2011

[6] Karpagam, S. and Agrawal, S., Existence of best proximity Points of P-cyclic contractions, Fixed Point Theory, 13 (2012), No. 1, 99-105

[7] Kirk, W., Srinivasan, P. and Veeramani, P., Fixed points for mappings satisfying cyclical contractive conditions, Fixed Point Theory, 4 (2003), No. 1, 79-89

[8] Meir, A., On the Uniform Convexity of $L_{p}$ Spaces, $1<p<2$, Illinois J. Math., 28 (1984), No. 3, 420-424

[9] Nordlander, G., The modulus of convexity in normed linear spaces, Ark. Mat., 4 (1960), No. 1, 15-17

[10] Păcurar, M. and Rus, I. A., Fixed point theory for cyclic $\phi$-contractions, Nonlinear Anal., 72 (2010), No. 3-4, $1181-1187$

[11] Petric, M., Best proximity point theorems for weak cyclic Kannan contractions, Filomat, 25 (2011), No. 2, 145-154

Plovdiv University "PAisi HILENDARSKI

FACULTY OF MATHEMATICS AND INFORMATICS

TSAR AsSEN No. 24, 4000 Plovdiv, Bulgaria

E-mail address: bzlatanov@gmail.com

Received: 02.06.2015; In revised form: 28.12.2015; Accepted: 04.01.2016

2010 Mathematics Subject Classification. 41A25, 47H10, 54H25, 46B20.

Key words and phrases. Best proximity points, uniformly convex Banach space, modulus of convexity, a priori error estimate, a posteriori error estimate. 